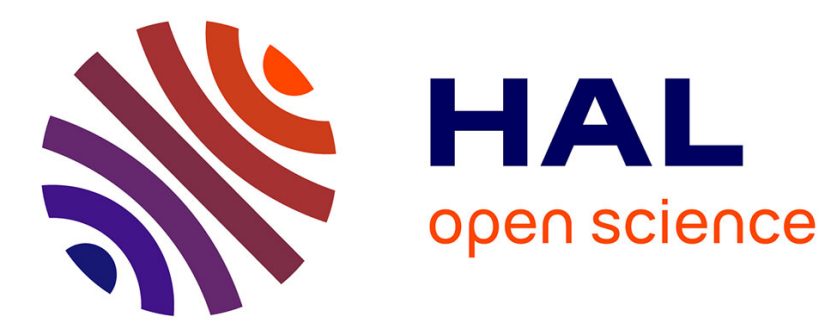

\title{
The effect of trade on agglomeration within regions Carolina Guevara
}

\section{To cite this version:}

| Carolina Guevara. The effect of trade on agglomeration within regions. 2015. halshs-01233389

\section{HAL Id: halshs-01233389 \\ https://shs.hal.science/halshs-01233389}

Preprint submitted on 25 Nov 2015

HAL is a multi-disciplinary open access archive for the deposit and dissemination of scientific research documents, whether they are published or not. The documents may come from teaching and research institutions in France or abroad, or from public or private research centers.
L'archive ouverte pluridisciplinaire HAL, est destinée au dépôt et à la diffusion de documents scientifiques de niveau recherche, publiés ou non, émanant des établissements d'enseignement et de recherche français ou étrangers, des laboratoires publics ou privés. 


\title{
GATE $_{\text {vossentromex }}$
}

UMR 5824

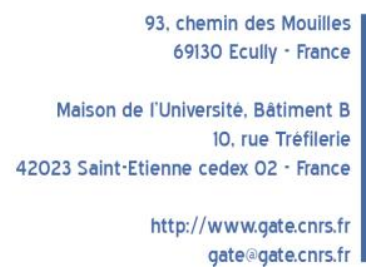

WP 1530 - November 2015

The effect of trade on agglomeration within regions Carolina Guevara

\begin{abstract}
:
This paper assesses for the first time the effect of regional trade openness on agglomeration within regions, using regional data on the trade of Colombia. The results of the panel model show that the effect of trade is sufficiently strong to shape the spatial configuration, a structure that rarely changes. The effect varies across regions. On the one hand, trade enhances spatial agglomeration within regions with large home market and location advantages. On the other hand, trade induces dispersion within regions that lack access to international trade or historical advantage. These results hold when controlling for the natural course of agglomeration (regions-pecific time trends), congestion effects in main cities and road infrastructure within regions.
\end{abstract}

\section{Keywords:}

Trade openness, spatial concentration, intra-inequality, congestion, cities, economic geography.

\section{JEL codes:}

$\mathrm{R} 12, \mathrm{~F} 10, \mathrm{O} 54$

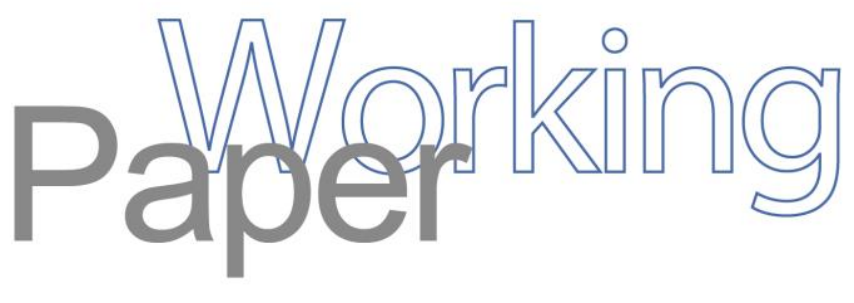




\title{
The effect of trade on agglomeration within regions
}

\author{
Carolina Guevara \\ University of Lyon, Lyon F-69007, France \\ CNRS, GATE Lyon Saint-Etienne, Ecully, F-69130, France \\ Université Jean Monnet, Saint-Etienne, F-42000, France. \\ e-mail: grace.carolina.guevara.rosero@univ-st-etienne.fr
}

\begin{abstract}
This paper assesses for the first time the effect of regional trade openness on agglomeration within regions, using regional data on the trade of Colombia. The results of the panel model show that the effect of trade is sufficiently strong to shape the spatial configuration, a structure that rarely changes. The effect varies across regions. On the one hand, trade enhances spatial agglomeration within regions with large home market and location advantages. On the other hand, trade induces dispersion within regions that lack access to international trade or historical advantage. These results hold when controlling for the natural course of agglomeration (regionspecific time trends), congestion effects in main cities and road infrastructure within regions.
\end{abstract}

Keywords: trade openness, spatial concentration, intra-inequality, congestion, cities, Economic Geography.

JEL Classification: R12, F10, O54

\section{Introduction}

Spatial concentration is a ubiquitous process in territories, being not only an inter-regional but also an intra-regional phenomenon. It has been widely argued that trade is one of the factors that influences such spatial configurations.

The understanding concerning spatial differences between regions induced by trade 
has been addressed largely in the New Economic Geography and in urban system theory. The literature underlines that openness to trade is one of the factors shaping the spatial configuration within countries because trade affects domestic regions according to their comparative advantages and factor endowments (Krugman, 1991; Krugman and Livas Elizondo, 1996; Krugman and Venables, 1995; Venables, 2005; Monfort and Nicolini, 2000; Rauch, 1991; Alonso-Villar, 1999; Paluzie, 2001).

Frequently, theoretical models are indifferently applied to the international context and to the national context because there is a lack of explicit distinction between regions and countries (Behrens et al., 2007) and a lack of information on sub-national regions. The regional distinction is not trivial because trade openness differently affects regions to the extent that tariffs are product-specific. Then, specialized regions in certain products will meet different costs depending on the incentives that tariff policies advocate. Thus, the spatial configuration of the economic activity between regions is likely to be modified. Moreover, the spatial configuration within regions is affected to the degree that agglomeration forces are quite localized (Head and Mayer, 2004). The process of concentration originates in cities, then shifts to the regional scale and the national scale (Hansen, 1990). Therefore, the analysis at the sub-national scale makes sense both from a theoretical and an empirical point of view. However, the empirical evidence has focused on the national scale rather than on the sub-national scale. The empirical analysis at finer geographical scales is compelling, providing interesting insights to be considered in theoretical studies.

Besides the geographical scope of the effect of trade, another important aspect that deserves special attention in the literature is the study of developing countries because it can boost development, diversification and innovation. This paper focuses particularly on the role of trade openness in the spatial configuration of cities within regions in Colombia.

In this country, the pattern of spatial concentration is a recurrent process across geographical levels, i.e., at the national level, few regions prevail, and at the regional level, few cities stand out. In the national context, more than half of national production is concentrated in only four regions that occupy $10 \%$ of the territory. Within regions, spatial concentration is also observed. On average, the most populated cities of regions are 4 times as large as secondary cities.

In the context of globalization, Colombia has experienced an increasing trend of trade liberalization. In the last decade, trade $^{1}$ has rapidly increased at an annual growth rate

\footnotetext{
${ }^{1}$ It is computed as the sum of exports and imports. The data are obtained from the Statistic System of International Trade (SIEX is the acronym based on the Spanish name).
} 
of $11 \%$ from US $\$ 21$ billion in 1999 to US\$78 billion in 2010. Concerning regions, trade has also been increasing (8.2\% annually on average). Such a trend of trade openness might affect spatial disparities. As discussed in more detail in Section 2, openness to trade could enhance concentration within regions through two effects: the home market effect and the location advantage effect. However, as far as Colombia, a developing country, is concerned, one may think that the patterns of concentration can be reversed with trade because export specialization in the agricultural goods of this country might reduce spatial disparities through an increase in income of primary-sector specialized regions (De-Ferranti et al., 1998).

Given those motivations, the aim of this paper is to examine the effect of trade on intra-inequality of Colombian regions. We employ a database whose richness relies on information on the international imports and exports of each region. Using such data together with complementary regional information on infrastructure, we contribute to assess for the first time the effect of regional trade openness on the spatial configuration within regions.

This paper is organized as follows. Section 2 reviews theory and empirics about the effect of trade on spatial inequality. Section 3 describes the stylized facts about regional concentration and trade openness in Colombia. Section 4 presents the methodology of estimation and the data. Section 5 discusses the results. Section 6 concludes.

\section{Is agglomeration influenced by trade?}

\subsection{Theoretical literature review}

The role of trade openness in the spatial configuration of countries has been largely studied. Most theoretical studies have been based on the New Economic Geography (NEG). This approach addresses the issue of the influence of openness on concentration of activities from two perspectives: heterogeneity of regions and homogeneity of regions. The former is of particular interest here because heterogeneity of domestic regions involves specific mechanisms (different production functions of each region) that can be neglected at the national scale.

Trade openness also has implications for the development of cities because economic 
activities commonly concentrate in urban areas. The closest approach concerning this perspective was undertaken in the early nineties through the analysis of urban systems examining the distribution of cities in an open economy (Henderson, 1982; Rauch, 1991). Recently, the understanding of why urbanization occurs in a trade process has been rebooted (Pellegrina, 2014; Fajgelbaum and Redding, 2014; Jedwab, 2013; Gollin et al., 2013). Therein, urbanization is revealed as an important result of trade openness that reinforces inequality patterns, which are predicted in the New Economic Geography.

NEG models commonly assume that the domestic economy has an internal structure with two regions ${ }^{2}$. By contrast, urban system models use cities as basic spatial units. Overall, the main aspects that explain spatial disparities in both models are comparative advantages and factor endowments of regions.

In the general set-up of NEG models, regions differ in terms of their location within a country, one region located deep inland, which is related to the rural area, and one region close to the sea, which is related to the urban are (Nishikimi, 2008). Theoretical predictions indicate that trade integration increases the concentration in the region with good international accessibility. Domestic firms locate close to the foreign market to spend less in transportation costs. Thus, trade enhances disparities between geographically advantaged and disadvantaged regions (Nishikimi, 2008; Alonso-Villar, 1999; Crozet and Koenig, 2004). Another centrifugal force that prompts economic activities to locate in border regions is the size of foreign markets (Alonso-Villar, 1999). If the external market (foreign countries) is large, border domestic regions benefit from a large external demand that, in turn, attracts more firms. The fact that the variety of products increases in border regions due to trading with foreign markets also attracts more workers. Thus, ports and border regions host the mobile activity because of their locational advantage (Alonso-Villar, 1999).

Nevertheless, Alonso-Villar (1999), Brülhart et al. (2004) and Crozet and Koenig (2004) establish that if agglomeration prior to openness allocates in the interior region, there will be no relocation toward the borders. The main reason is that historical factors more than offset the effect of trade. If foreign countries are small, firms will not be interested in locating in border regions; the firms will instead follow historical factors, i.e., the extant pattern of agglomeration (Alonso-Villar, 1999). Moreover, being near to

\footnotetext{
${ }^{2}$ Multi-regional models have been developed. However, most of them retain the setting of two regions within one country except for Alonso-Villar (1999), who set three regions in the same country. Other models illustrate a setting with more than three regions (Akamatsu et al. (2012); Ikeda et al. (2012) and Ikeda et al. (2014)).
} 
the foreign market implies more competition for domestic firms, so these firms search to locate as far as possible from foreign competitors. In that case, trade integration favors agglomeration toward internal regions (Alonso-Villar, 1999; Crozet and Koenig, 2004).

Concerning urban system theory, Rauch's (1991) model considers that population agglomerates around the centers of cities; thus, one central business district (CBD) exists in each city. Workers that live far away from the CBD must pay high commuting costs but lower land rents. They have the incentive to go to the CBD to interact with other workers and shopping. Cities produce goods ranked according to their comparative advantage. As in NEG models, cities differ in terms of their distance to the coast, and they are located along a river (straight line). The price of imported goods from foreign cities is higher in domestic inland cities than in domestic coastal cities because inland cities face higher transportation costs. The higher prices lead to low purchasing power in inland cities, which induces people to move to coastal cities. In the presence of prohibitive trade costs, purchasing power in all cities is constant; thus, all cities have the same size. As trade costs decrease, cities engage in international trade, and their sizes will be higher depending on their closeness to the coast, as shown in Figure 1.

Figure 1: Distribution of cities after trade openness, Rauch (1991)

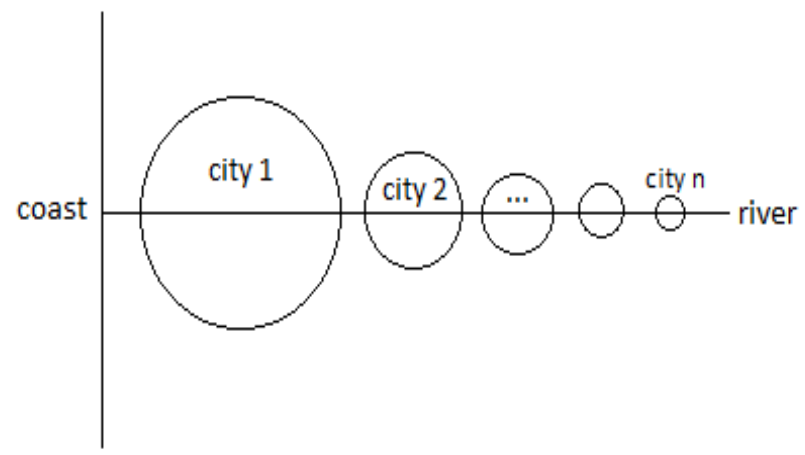

Source:Rauch (1991)

In the process of trade, the distinction of economic sectors is another important aspect. Fajgelbaum and Redding (2014); Pellegrina (2014); Gollin et al. (2013) consider this distinction and observe three sectors: the tradable agriculture sector located in the ru- 
ral area, the tradable manufacturing sector and the non-tradable services/manufacturing sectors located in the urban area. There are two locations with different underlying characteristics: interior regions and coastal regions. The regions closer to the sea (comparative advantage) face lesser transport costs (Fajgelbaum and Redding, 2014). The key finding of the model refers to the so-called Balassa-Samuelson effect. In the case of trade openness, locations with good access to the international market will have a higher share of employment in the non-tradable sector (located in the urban area), higher population density and higher aggregate income. Thus, this model identifies urbanization as a characteristic of agglomeration resulting from trade openness.

Briefly, theoretical insights about the effect of trade on the spatial distribution of activities assuming homogeneous regions are exposed. There is a mixed set of predictions concerning the effect of trade on agglomeration due to the underlying assumptions about dispersion and agglomeration forces (Behrens et al., 2007). On the one hand, trade induces agglomeration (Krugman, 1991; Paluzie, 2001; Monfort and Nicolini, 2000) in models considering explicit costs as the dispersion force. Explicit costs refers to the transport costs that firms must face according to their production function to reach the dispersed demand. In the original model of Krugman (1991), the region with the manufacturing activity will gain more agglomeration through the backward linkage, which is the home market effect (expenditure in manufacturing goods), and the forward linkage, which comprises higher wages. The dispersion force is the competition in the local market. Below a critical level of transportation costs, the concentration of manufacturing production in one region is at equilibrium. Such a region attracts more workers and firms due to higher wages and lower cost of living. Thus, regional divergence is enhanced with trade openness. On the other hand, Krugman and Livas Elizondo (1996) show that trade induces dispersion. This result is different because implicit costs are considered the dispersion force. Implicit costs refers to congestion effects in cities. In their model, the concentration in one region vanishes with the reduction of trade costs because backward linkages (the demand in the home market) and forward linkages (inputs of other firms) become weaker. Exporting and importing firms that serve the external market do not have incentives to locate in the economic center, close to the local market. Moreover, high urban costs (congestion) in the local market discourage them from agglomerating. Thus, a process of de-concentration occurs. This result follows the local centrifugal force only? congestion effects. However, a global centrifugal force is required to determine how external trade affects the internal spatial configuration of a country. This aspect is considered by Alonso-Villar (1999), who shows that the prediction of Krugman and Livas Elizondo (1996) is a particular case of 
a general model considering both the global centrifugal force and the local centrifugal force. The global centrifugal force refers to the size of foreign countries. If the global force is large, i.e., population in foreign countries is large, the activity agglomerates in border regions. Here, the relocation of activities to border regions is explained by the size of external markets (global centrifugal force), whereas in Krugman and Livas Elizondo (1996), the relocation of activities is explained by congestion effects (local centrifugal force).

Based on the predictions of both types of models, explicit dispersion forces (transportation costs) appear to play a secondary role compared with the negative externalities produced in cities.

For practical purposes, the consideration of cities in the models of Rauch (1991), Krugman and Livas Elizondo (1996) and Alonso-Villar (1999) merits special attention. The relocation of activities is assumed to occur between contiguous cities. Then, the results of these models can be transposed to lower geographical scales than the national one.

The interest of this study is to determine whether trade openness shapes the spatial configuration within regions. The intuition is as follows. The main city within one region has the largest market, which represents its advantage in terms of access to the international market. The main city will concentrate further population when trade increases because the production of small cities must be transported to/from the main city to be exported/imported. However, if the main city faces congestion diseconomies, exporting and importing firms will prefer to locate outside the main city to avoid high labor and land costs. Furthermore, firms undertaking exporting/importing activities would not be interested in locating near the largest local market because their inputs and demand come from abroad, i.e., weak backward and forward linkages.

\subsection{Empirical literature review}

Empirical studies about trade and inequality use two types of datasets: cross-country data and within-country data. In the former, external trade of countries is examined to disregard the different levels of trade of domestic regions. Such heterogeneity within countries is considered in the analysis using within-country data.

Reference studies using cross-country data are Ades and Glaeser (1995) and Hender- 
son (2000). Those studies analyze the factors influencing the level of inequality, which is measured by urban primacy in each country. The common explanatory variables of their models are per capita income, trade openness, capital dummy, land area, transport investments and institutions. Both models show a significantly positive effect of per capita income and the capital city dummy and a negative effect of transport investment on urban primacy. With respect to institutions, Ades and Glaeser (1995) show that "urban giants" are the result of power concentration in the context of dictatorships. Likewise, Duranton (2007) states that primacy city favoritism is a factor that causes excessive concentration in developing countries. Henderson (2000) found a weak downward effect of federalism on urban concentration. The effect of trade openness seems to be unclear in those models. In Ades and Glaeser (1995), the estimate of openness becomes insignificant in the instrumental variable model. In Henderson (2000), given that the effect of trade openness is generally but not always negative, an interaction variable between trade and a port dummy is introduced. However, the change in the effect of openness is modest. Similarly, Brülhart and Sbergami (2009) in an attempt to test the hypothesis of Krugman and Livas Elizondo (1996) found inconclusive results concerning the effect openness in the growth-agglomeration relationship. Ramirez-Grajeda and Sheldon (2009) analyze a sample of 84 countries. Their results show that main cities decrease in size, whereas secondary cities grow when trade openness increases. These results are in line with the Krugman and Livas Elizondo's (1996) prediction.

Using within-country data, the effect of trade is clearer. The prediction that manufacturing would locate in the core of the country with geographical advantage leading to regional inequality has been verified for China (Ge, 2006; Kanbur and Zhang, 2005). Based on the methodology of location choices, Henderson and Kuncoro (1996) conclude that trade liberalization enhances the degree of spatial concentration of manufacturing in large metropolitan areas but centralization is difficult to alter due to historical patterns in Indonesia. The administrative and spatial hierarchies are some of those historical factors.

The evidence concerning the effect of trade on spatial disparity in Latin American countries is scanty, except for Mexico, which has attracted the attention of community researchers due to the emergence of one of the largest cities in the world, the Mexico Federal District. Several empirical studies have been conducted to disentangle the mixture of theoretical predictions of Krugman (1991), Paluzie (2001) and Monfort and Nicolini (2000), on the one hand and that of Krugman and Livas Elizondo (1996), on the other hand. The evidence generally shows that after the process of trade liberalization in Mexico, bor- 
der regions (US frontiers) have gained attractiveness, leading to dispersion of activities that were initially concentrated in Mexico city (Hanson, 1997; Madariaga et al., 2014; Chiquiar, 2005; Aroca et al., 2005; Jordaan and Rodriguez-Oreggia, 2012). Likewise, in the Argentinean case, Sanguinetti and Volpe-Martincus (2009) have noticed that the high concentration of manufacturing industries has decreased between 1974 and 1994. The authors relate this process of de-concentration to trade reforms. The econometric results confirmed that employment grew more than proportionately in regions far away from the economic center, namely the region of Buenos Aires. The reason is the congestion effects derived from over-concentration in this economic center. This result supports Krugman and Livas-Elizondo's (1996) hypothesis. By examining regional inequality over time, Daumal (2010) also showed that trade openness contributes to regional convergence in Brazil.

Other empirical investigations are conducted through the calibration of theoretical models of Fajgelbaum and Redding (2014); Pellegrina (2014); Jedwab (2013); Gollin et al. (2013). Along these lines, Fajgelbaum and Redding (2014) provide evidence for Argentina and Pellegrina (2014) for the Brazilian Amazon region. Fajgelbaum and Redding (2014) verified the Balassa-Samuelson effect by assigning values to some parameters of the model (land intensity, elasticity of the demand between tradables and non-tradables and preference weight) and using data on population density, distance to Buenos Aires (access to world markets), urban population and agricultural/non-agricultural productivity. Jedwab (2013) investigated the effect of crop exports on urbanization for the Ivory Coast and Ghana. The results show that the rate of urbanization increases with exports.

In conclusion, the vast theoretical literature of the New Economic Geography provides insights about the effect of trade on agglomeration by considering two regions. Such a framework sheds light on inter-regional inequality. However, spatial inequality also emerges within regions. The consideration of cities instead of regions is a key element that the model of urban systems (Rauch, 1991) introduces, allowing a better understanding about intra-regional inequality. Overall, the underlying characteristics of regions and increasing returns to scale are the factors that determine the spatial configuration.

The empirical literature addresses the effect of trade using two types of databases: cross-country and within-country data. Studies using cross-country data show mixed results concerning the effect of trade on spatial inequality within countries. Studies using within-country data, considering that trade could produce different effects according to the openness to trade of domestic regions, find that trade increases spatial inequality. Overall, inter-regional inequality is observed, but inequality may also arise within re- 
gions. Until now, there has been no focus on this issue in the empirical literature. This aspect requires more analysis because agglomeration is a recurrent pattern across the geographical levels. AsVenables (2005) states, spatial concentration occurs much more at an inner-spatial level than at the state or province level. Turning attention to a regional level, we attempt to fill the void in the empirical literature using sub-national data of Colombia. The next section describes the context of spatial inequality in this country.

\section{Spatial inequality context in Colombia}

In Colombia, spatial agglomeration is not only an inter-regional but also an intra-regional phenomenon. This section describes the mechanisms that have led to both structures.

Globalization has been one of the key factors that shaped the spatial distribution of population in the country. The spatial organization in function of fertile lands (comparative advantage) has led to the positioning of four main cities, two in the mountainous region, Bogota and Medellin, and two on the Coast, Cali and Baranquilla. Currently, the production of Colombia (GDP of 548.3 thousands of millions of pesos, equivalent to US\$ 291 billion in 2010) remains highly concentrated. Bogota Capital District, with a surface area corresponding to $0.14 \%$ of the total territory $(1776 \mathrm{~km} 2$ out of 1141748 $\mathrm{km} 2$ ) records $26 \%$ of the national production. Excluding Bogota Capital District, three other regions, Antioquia (capital city Medellin), Valle (capital city Cali) and Santander (capital city Bucaramanga) account for $31 \%$ of the national production and occupy $10 \%$ of the national territory. The 12 regions with shares less than $1 \%$ all together reached only $4 \%$ of the total GDP. However, they occupy $51 \%$ of the total national surface.

The pattern of development of cities in the territory has gone hand in hand with geographical characteristics. To observe such a configuration, the elemental structure of

Colombia is considered. That structure divides the national territory in 6 large elemental regions as shown in Figure 2. 
Figure 2: Elemental structure of Colombia

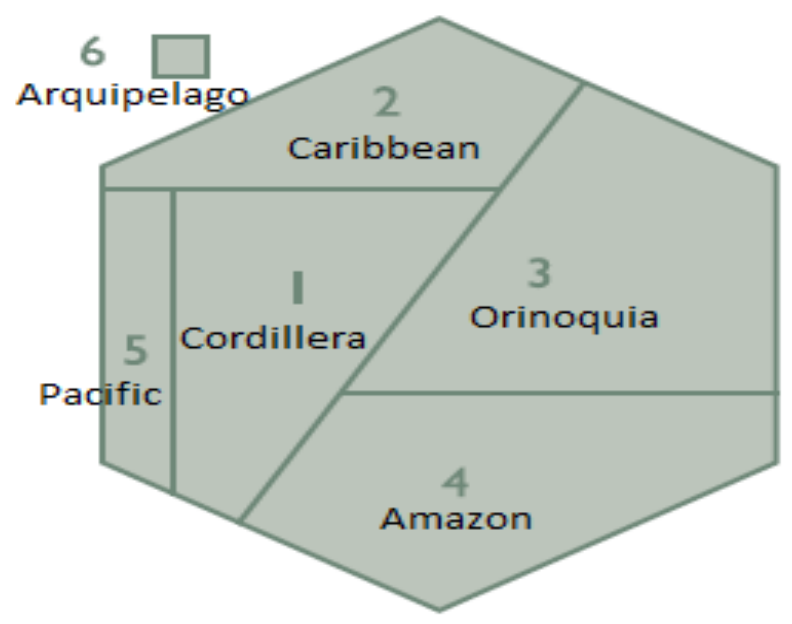

Source: Massiris-Cabeza et al. (2012) on the basis of Deler (1991) and Flórez (2003)

The Cordillera elemental region gathers most of the cities, 735 , which concentrate $62 \%$ of the national population. The Caribbean elemental region has 237 cities and concentrates $31 \%$ of the total population. The Pacific elemental region has 30 cities with $1 \%$ of the total population. The rest of the elemental regions (Orinoquia, Amazonas and Archipelago) record 120 cities with only $6 \%$ of the total population despite the fact that Orinoquia and Amazonas occupy $50 \%$ of the territory, approximately. ${ }^{3}$ Thus, population is highly concentrated.

Within regions, some cities constitute the cores of attraction because they provide better standards of living, whereas other intermediate cities feed those centers through production, and other cities remain unconnected due to accentuated poverty issues. Therefore, spatial disparities are also observed at the intra-regional level. The main centers of agglomeration have developed communications, transport infrastructure and urban conditions, which have prompted internal migrations, particularly from rural to urban areas, fostering the agglomeration within regions. Examining population shows that most regions have predominant cities that account for more than $50 \%$ of the regional population. On average, the most populated cities within regions are 4 times as large as secondary

\footnotetext{
${ }^{3}$ Note that some regions can be classified in two elemental regions because they are in the Cordillera and have either the Pacific coast or the Caribbean coast. We classify regions according to the location of the main city to avoid duplicates.
} 
cities. The density ${ }^{4}$ (traffic per kilometer) on roads surrounding capital cities is on average 3 times greater than the density on roads far from capital cities. This fact confirms that small cities feed the largest cities to the degree that production and population commute more often toward them, enhancing the concentration within regions. In Figure 3, the case of one region, Antioquia, is presented. We can observe that the traffic volume is greater closer to the capital city, Medellin.

Figure 3: Traffic volume in Antioquia-Colombia

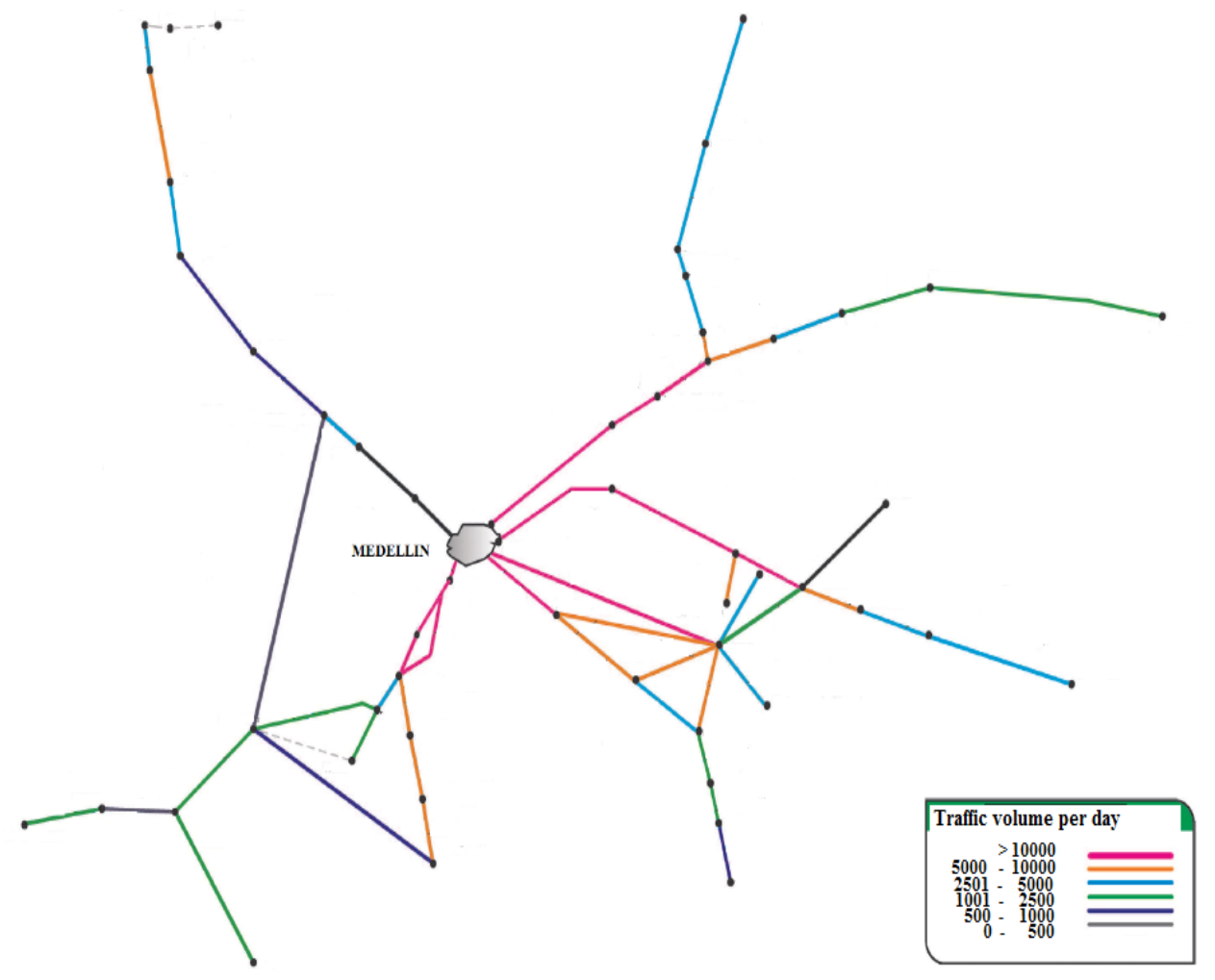

Source: INVIAS (2012)

The presence of illegal armed forces, commonly related to narco-traffic, is another element that induced people searching for safety to locate in specific cities. Although

\footnotetext{
${ }^{4}$ The information was obtained from the National Institute of Roads of Colombia, which collects the information about traffic volumes during the year.
} 
this fact could influence the disparity within regions, it rather affects the spatial disparity between regions. According to the human risk index developed by the United Nations Office for the Coordination of Humanitarian Affairs, the least-safe cities are located in the region of Choco (a coastal region of the Pacific Ocean) and in Norte de Santander, Arauca and Narino (border regions). Hence, population would move to other regions rather than to other cities within those unsafe regions.

After all, Colombia presents not only spatial disparities between regions but also within them. To measure both types of inequality, we apply the Theil index using population of cities. It is computed with the following formula:

$$
T=\sum_{c=1}^{C} \frac{A_{c}}{A} \log \frac{A_{c}}{A / C}
$$

where $A$ is the total population in the country, $A_{c}$ is the population in city $c, C$ is the total number of cities in the country. It is noteworthy that $A / C$ is the counterfactual, in which cities are equipopulous. This index can be decomposed in inequality between regions and inequality within regions as follows:

$$
\begin{aligned}
& \text { T }=\text { Tintra }+ \text { Tinter } \\
& \text { Tintra }=\sum_{i=1}^{R} \frac{A_{i}}{A}\left(\sum_{c}^{C_{i}} \frac{A_{c}}{A_{i}} \log \frac{A_{c}}{A_{i} / C_{i}}\right) \text { and } \\
& \text { Tinter }=\sum_{i=1}^{R} \frac{A_{i}}{A} \log \frac{A_{i} / C_{i}}{A / C}
\end{aligned}
$$

where $A_{i}$ is the population in region $i$ and $C_{i}$ is the number of cities in region $i$.

The overall Theil index of Colombia indicates that the spatial concentration of population is high, having increased from 1.68 in 1999 to 1.75 in 2010. The share of inequality within regions measured using the Theil intra-index (52\%) was slightly greater than the inter-regional inequality measured using the Theil inter-index (48\%). This result confirms that spatial agglomeration in Colombia arises at both inter-regional and intra-regional levels.

The mechanisms underlying spatial inequality have been closely related to trade open- 
ness of the country ${ }^{5}$. The aforementioned transport and urban infrastructure were built largely because of the exigencies of international demand. Because few regions benefit from such an investment, spatial disparities were enhanced. Currently, five regions of Colombia account for $40 \%$ of total exports and $84 \%$ of imports, approximately. The regions concentrating most of the export activity are primarily Antioquia and Bogota, followed by Cesar, Cundinamarca, Guajira and Bolivar. Import activities are primarily concentrated in Bogota, followed by Antioquia, Valle, Cundinamarca and Bolivar. Most regions have experienced an increase in international trade during the last decade. The five regions with the highest average annual growth rates of trade are Quindio (27\%), Huila (25\%), Choco (22\%), Cesar (20.6\%) and Norte de Santander (19\%). Only a few regions, particularly those located in the Amazon and Orinoquia, had negative average growth rates of trade in the period 1999-2010.

The simple correlation between the intra-inequality of regions (Theil intra) and regional trade is significantly positive (0.58). The higher the level of trade, the higher the level of inequality within regions. Thus, we might think that spatial configuration within Colombian regions is related to trade openness.

Given these observations, the next section investigates to what extent trade shapes the spatial configuration within Colombian regions.

\section{Model and data}

Colombia records trade data at the regional level, allowing us to assess for the first time the effect of regional trade openness on agglomeration within regions. We use panel data of 32 regions over the period 1999-2010.

\footnotetext{
${ }^{5}$ At the initial stage of trade liberalization, Colombia signed regional South American agreements: the Andean Community (Ecuador, Bolivia, Peru and Venezuela) in 1969 and agreements with some Central American countries. The trade openness primarily rose with the accession to the General Agreement on Tariffs and Trade/World Trade Organization (GATT/WTO) in 1981. This country was conducting unilateral trade liberalization (Koujianou-Goldberg and Pavcnik, 2007). Later, Colombia signed trade agreements with the European Free Trade Association, EFTA (Iceland, Liechtenstein, Norway, and Switzerland) in 2008; with Canada in 2011; with United States in 2012 and with the European Union together with Peru in 2012.
} 
As shown in Section 3, the patterns of concentration depend upon the natural or other characteristics of regions that are present but not always observable. To control for unobserved heterogeneity, we use panel data techniques.

The specification of the panel model is the following:

$$
\begin{aligned}
\operatorname{agglom}_{i t} & =\alpha+\lambda \text { openness }_{i(t-s)}+X_{i t} \beta+\theta_{t}+\rho_{i} t+\eta_{i, t} \\
\eta_{i, t} & =\mu_{i}+\varepsilon_{i t}
\end{aligned}
$$

where agglom $_{i t}$ is the level of agglomeration within region $i$ at time $t$, openness ${ }_{i(t-s)}$ is the trade openness of region $i$ at time $t-s, X_{i t}$ is the row vector containing control variables, $\mu_{i}$ represents region-specific effects, $\theta_{t}$ corresponds to time-specific effects, $\rho_{i} t$ represents region-specific time trends and $\varepsilon_{i t}$ is the well behaved independent identically distributed error. Since unique characteristics of regions would be correlated with trade openness and control variables, the assumption of the OLS estimator that $\operatorname{cov}\left(\eta_{i, t}, X_{i t}\right)=0$ is violated. Then, OLS estimates are biased and inconsistent. The fixed effects estimator is therefore appropriate. When $\mu_{i}$ is assumed fixed and the remaining disturbances are stochastic with $\varepsilon_{i t}$ independent and identically distributed with mean zero and a constant variance, the fixed effects model is an appropriate specification. The second case is to assume that individual effects, $\mu_{i}$, are random. To choose between fixed effects model or random effects model, the Hausman test will be used. In the sequel, the variables used in the model are described in detail.

\section{Dependent Variable}

Agglomeration is measured with the Theil index of population ${ }^{6}$ proposed by Theil (1967). As presented previously, the Theil index can be decomposed into two indexes distinguishing intra-regional and inter-regional concentration. To capture the concentration of population within regions, we use the Theil intra-index. The formula is as follows.

\footnotetext{
${ }^{6}$ In this case, we consider inequality a mere demographic phenomenon. Spatial inequality also involves differences in the standard of living between localities. Data on income of cities would solve this issue. However, obtaining such information for large periods is complicated.
} 


$$
T_{i}=\sum_{c=1}^{C_{i}} \frac{A_{c}}{A_{i}} \log \frac{A_{c}}{A_{i} / C_{i}}
$$

where $A_{c}$ is the population in city $c, A_{i}$ is the total population of region $i$ and $C_{i}$ is the number of cities of region $i$. The index is computed at each period $t$. The term $A_{i} / C_{i}$ is the counterfactual or situation of reference in which all cities are equipopulous. A higher value of the index indicates a higher degree of concentration within a region. To construct said index, we employ information on the population of cities within regions.

This variable of agglomeration is consistent with theoretical models analyzing the proportion of workers located in one region after trade openness. We also considered other indexes to measure agglomeration intra-regions such as primacy, the standard deviation and the coefficient of variation. However, those measures have limitations. For instance, primacy disregards the weight of secondary cities in regions. The standard deviation measure does not consider a reference distribution of cities. These measurement issues are solved when using the Theil index.

The Theil index comprises information of approximately 1122 municipalities ${ }^{7}$ spread over 32 regions of Colombia. The number of cities by region ranges from 2 cities (San Andres) to 124 cities (Antioquia). Because the Theil index is computed using the administrative division, economic agglomerations could be artificially separated and the so-called Modifiable Areal Unit Problem (MAUP) could arise. However, the Theil index appears to consider implicitly the economic agglomeration of cities. Moreover, population might not locate in city frontiers because of infrastructure barriers. Thus, concentration patterns within regions might be well represented by the administrative division.

As shown in Table 1, the variation of the population Theil index comes largely from heterogeneity across regions. For instance, Valle del Cauca, which has 42 cities, concentrates more than $50 \%$ of its total population in one city only. An example of regions with low levels of concentration is Putumayo, whose cities exhibit population shares around the counterfactual. The (within) variation across time is small, which shows that the pattern of inequality is permanent over time.

\footnotetext{
${ }^{7}$ In this study, cities are defined by municipalities, which correspond to the second level of the administrative division in the country.
} 
Table 1: Variation of the Theil-intra index

\begin{tabular}{lccccc}
\hline Variable & variation & Mean & Std. dev. & Min & Max \\
\hline $\operatorname{Tr}$ & overall & 0.77 & 0.3799 & 0.20 & 1.60 \\
& between & & 0.3849 & 0.21 & 1.59 \\
& within & & 0.0208 & 0.69 & 0.89 \\
\hline
\end{tabular}

\section{Explanatory Variables}

Trade openness $\left(\right.$ Open $\left._{t-2}\right)$ is computed as the logarithm of the sum of imports and $\operatorname{exports}^{8}$. Another interesting measure of openness is the level of import duties. However, we do not account for such data. As in Henderson (2000) and Ades and Glaeser (1995), we use a two-year lag of openness. The effect of openness on regional inequality is likely to be delayed because the re-organization of exporting and importing firms responding to trade policies takes time. We have estimated different specifications using different time lags of openness ${ }^{9}$, and a two-year lag of openness is chosen because it fits the data better. Moreover, we do not lose observations using such a lag. As shown previously in Section 3, regional trade differs in terms of exports and imports. Therefore, we distinguish trade openness in exports $\left(\right.$ Exports $\left._{t-2}\right)$ and imports $\left(\right.$ Import $\left._{t-2}\right)$. Both variables are also in logarithm form.

Concerning the expected effect of trade on intra-inequality of regions, the theoretical literature considering the role of cities is appropriate. According to this literature, namely Rauch's (1991) model and the Krugman and Livas Elizondo's (1996) model, the effect of openness on inequality is ambiguous. Two distinct effects may arise.

On the one hand, the coefficient estimate would be positive according to the prediction that economic integration leads to concentration of population in cities with better access

\footnotetext{
${ }^{8}$ Other alternative measures that we use are the sum of imports and exports as share of GDP, the share of exports over GDP, the share of imports over GDP and the volume of exports plus imports. The estimation results are available upon request to the author.

${ }^{9}$ The results of estimations using different lags are available if requested of the author. According to the results, the coefficient estimates of the interaction terms between Open and Cordillera and the Coast are stable across regressions. Because the agglomeration pattern is not very sensitive in a short time, we do not use the first lag of openness. The estimation's results using the third lag of openness are similar to the estimations using the second lag of openness. Finally, the estimation using the fourth lag of openness loses observations. Overall, we choose the second lag of openness for the estimations.
} 
to the international market. According to Rauch's (1991) model, cities are located along a river, and those that are near to the coast will concentrate population when trade costs are low. Analogously, the spatial distribution of cities within regions in Colombia is the following (see figure 4). In this configuration, each region has many cities. Among them, large cities have the advantage of closer connection to the international market because of their size.

Figure 4: Distribution of cities within regions

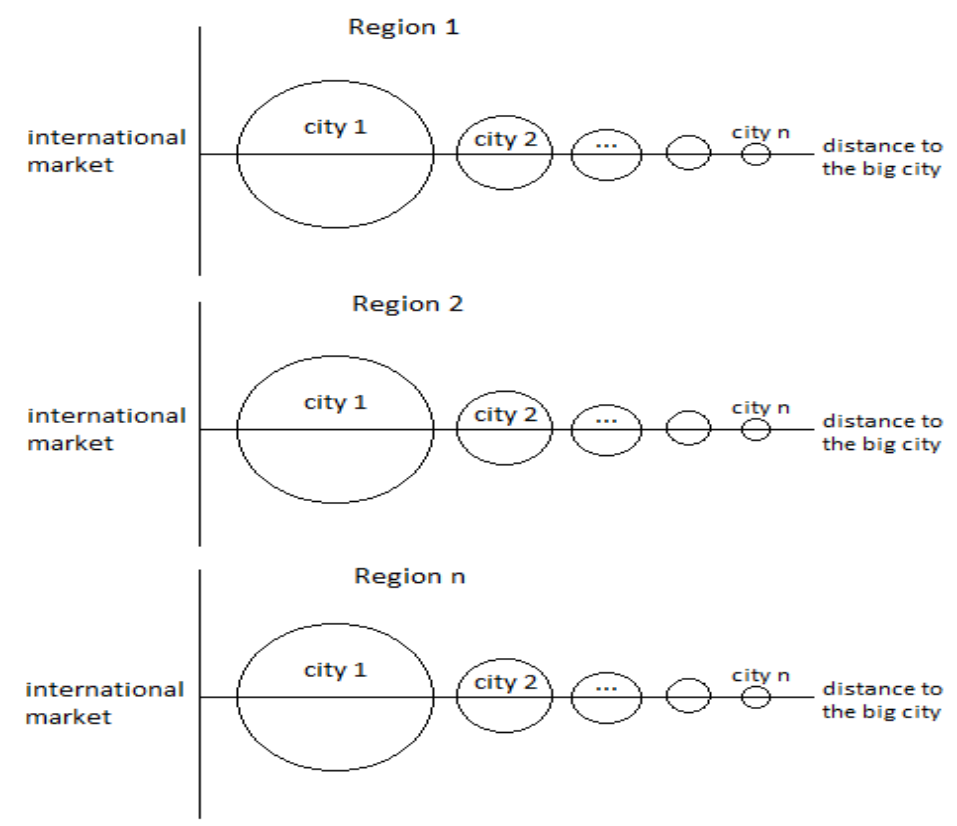

Based on Rauch (1991)

In the graph, the distance to the coast is transposed to the distance to the international market. Larger cities have a higher degree of access to the international market. Moreover, the notion of the distance to the coast is retained in our analysis. Thus, cities of inland regions have one single centripetal force, whereas cities of regions near the coast have two centripetal forces. The force affecting both types of regions is the home market effect corresponding to city sizes. The additional force of coastal cities is the location advantage effect corresponding to their geographical position with respect to the international market. Hence, the expected effect of trade on intra-inequality would be greater for coastal regions. 
By recalling the statistics shown in Section 3, we presume that inland regions will also experience more concentration induced by trade because the largest cities of the country are interior (Fernandez, 1998) and trade would reinforce them. This presumption holds for regions in the Cordillera because of historical factors. Most of their cities have been historically favored in the national configuration. Then, as Alonso-Villar (1999), Brülhart et al. (2004) and Crozet and Koenig (2004) state, , the effect of openness would depend upon the initial agglomeration of these regions. On the other hand, regions in the Amazon and Orinoquia are presumed to experience a lower effect of trade because their geographical characteristics comprising the rain forest and the countryside impede, to some extent, agglomeration. Moreover, the presence of illegal armed forces related to narco-traffic is another factor that could discourage economic activities from concentrating in these regions.

To test whether the effect of trade depends upon the geography of regions, we introduce interaction terms between trade openness and region types following the elemental geography of the country ${ }^{10}:$ 1) Cordillera $\left.{ }^{11}, 2\right)$ The Coast (The Caribbean and the Archipelago) ${ }^{12}$ and 3) Orinoquia and Amazon ${ }^{13}$.

Based on the above-mentioned intuitions, we expect the interaction term between trade and the Cordillera dummy (Cordillera $*$ Open $_{t-2}$ ) and the interaction term between trade and the Coast dummy (Coast $*$ Open $_{t-2}$ ) to be positive for concentration of population within regions, and to be greater than the interaction term between trade and the Amazon and Orinoquia dummy ${ }^{14}$.

The coefficient estimates would be negative according to the prediction that backward and forward linkages become weaker when trade costs decrease. The presence of conges-

\footnotetext{
${ }^{10}$ Regions are classified in one of the categories according to the position of their main city. In this manner, the issue of a region sharing two elemental regions is solved.

${ }^{11}$ The regions classified in the Cordillera are Antioquia, Boyacá, Caldas, Cauca, Cundinamarca, Huila, Nariño, Norte de Santander, Quindio, Risaralda, Santander and Tolima.

${ }^{12}$ The regions classified in the Coast are Atlántico, Bolívar, César, Córdoba, La Guajira, Magdalena, San Andrés, Sucre and Valle del Cauca.

${ }^{13}$ The regions classified in the third group are Amazonas, Arauca, Caquetá, Casanare, Choco, Guainía, Guaviare, Meta, Putumayo, Vaupes and Vichada. The region Chocó of The Pacific is classified in this group because its capital city is far away from the coast. Furthermore, it has problems of menace that lead to low levels of agglomeration of population. Hence, it is not expected to experience concentration.

${ }^{14}$ Note that including a dummy variable for Amazonian regions allows, to some extent, controlling for unobserved narco-traffic activities in these regions. We think that the presence of such activities could inhibit agglomeration of population because of restrictions imposed by drug-dealers.
} 
tion effects in main cities might be another factor that could entail a decreasing effect of trade on spatial concentration (Krugman and Livas Elizondo, 1996).

In each of these situations, the effects of trade must exceed the levels of influence of historical factors (Henderson, 1994) to produce a change, either positive or negative, on concentration patterns.

Note that openness could be endogenous by reverse causality. High levels of population concentration in one region may influence its level of trade. When population concentrates in a few cities within regions, export and import activities increase in those cities because of labor availability and forward and backward linkages. However, because our dependent variable is an index, it is unlikely to exhibit a feedback effect. To be sure, we test whether this variable must be considered endogenous in our estimation.

Concerning the other control variables of our specification 1, we include time-invariant factors that affect inequality through region-specific effects $\left(\mu_{i}\right)$. Those factors could be the specific geographical characteristics of regions. Moreover, we control for factors that change over time but not across regions, that is, time-specific effects $\left(\theta_{t}\right)$. These effects could be related to national regulations, which are likely to affect all regions to the same degree. More importantly, we include region-specific time trends $\left(\rho_{i} t\right)$ to control for the natural growth of population. One can reasonably believe that concentration of population in main cities of regions would have an increasing trend because the native population increases regardless of the level of migration from other cities. The increase of population would be larger in the main city than in other cities because the main city already has a large population. Including time trends of each region allows determining the effect of trade net of such a natural course of agglomeration.

In the $X$ vector of control variables, we introduce other key variables that change over time and affect the level of agglomeration. One of them is congestion effects (congestion) in the main city of a region. These effects are measured by the annual growth rate of the daily average public urban transportation in service in the capital city of each region. In this manner, we are able to consider the key element of Krugman and Livas Elizondo's (1996) model, congestion. In the presence of this element, the prediction of such a model is that trade openness will incentivize firms to relocate far away from congested cities because their interest is no longer the local market but instead the foreign market. Once we control for congestion in the main city, we are able to determine whether congestion 
effects are sufficiently strong to influence the effect of trade.

Additionally, we control for internal transport infrastructure (traffic_density tr-2 $_{2}$ ), which is proxied by the traffic density in region $i$, the logarithm of the number of vehicles per kilometer within each region. As discussed in Section 3, road traffic seems to reinforce spatial disparities within regions. According to Puga (2002), an improvement in communications between two cities is not only beneficial for small cities but also for large ones. The small city would have better access to inputs and main markets, but the large city would also extend its market and more easily supply the small one. Then, the expected effect in the intra-inequality of regions is ambiguous. We use a two-year lag of transport infrastructure because economic interconnections driven by road infrastructure would develop over time.

\subsection{Data}

In terms of data sources, the information on exports and imports in FOB prices was obtained from the Statistic System of International Trade (SIEX for the acronym in Spanish) developed by the Taxes and Customs National Service (DIAN acronym in Spanish) of Colombia. Data on population of cities were obtained from the National Administrative Department of Statistics (DANE acronym in Spanish). The information on urban transportation in capital cities was obtained from the Survey of urban transport of passengers (ETUP acronym in Spanish) of Colombia, which accounts for information of 23 capital cities. The sample is reduced from 32 regions to 22 regions $^{15}$ when using this variable. Road traffic is obtained from the Report of the National Institute of Roads (INVIAS, 2012), which records the traffic volume in the main road network of the country. Finally, the classification of regions according to their elemental geography is based on the propositions of Deler (1991) and Flórez (2003).

Concerning data issues, our sample contains information of 32 regions instead of 33 regions. Bogota Capital District is excluded in this analysis for two reasons. First, the value of inequality within this region cannot be computed because the region has only one

\footnotetext{
${ }^{15}$ Capital cities of the ETUP survey include Bogota Capital District. In our sample, we exclude Bogota; therefore, the resulting sample when using this variable records 22 regions. Regions without information are Amazonas, Arauca, Casanare, Cundinamarca, Guainia, Guaviare, Putumayo, San Andres, Vaupes and Vichada
} 
city. Second, statistics of trade are not disaggregated for Bogota before 2004. Eliminating Bogota, an important district in Colombia, does not constitute a problem because the interest of our study is to analyze the intra-inequality of regions. Doing so would have been problematic in the case of the analysis about inter-regional inequality.

Another possible data issue is related to the destination of imports. One can think that imports are registered in main city ports and then re-distributed to other regions. Thus, the destination of imports would be misleading. According to the Taxes and Customs National Service (DIAN acronym in Spanish) of Colombia ${ }^{16}$, import forms record the main address (region and municipality) of the importer. The fact that import goods are registered in sub-national regions (not only in ports) reduces the uncertainty about import destinations within the country. Hence, this problem would be minor in our database.

\section{Results}

To estimate equation 1 presented in the previous section, the fixed effect (Least Square Dummy Variable, or LSDV) estimator is used. The motivation to use such a technique is the presence of region-specific effects that may be correlated with trade openness and control variables. In that situation, the fixed effects estimator is consistent. In addition, we use robust standard errors that allow for intra-group correlation. Robustness checks concerning stability ${ }^{17}$ and endogeneity ${ }^{18}$ are also conducted.

The results of our estimation are shown in Table 2 . In column (1), the specification of the model 1 with $\theta=0$ and $\rho=0$, i.e., without time-specific effects and region-specific time trends, is estimated. In column (2), the specification with $\theta \neq 0$ and $\rho=0$, i.e., without temporal trends of regions, is estimated. In column (3), the specification of the

\footnotetext{
${ }^{16}$ We have requested such information from DIAN and we have received formal response N. 100210226 2401.

${ }^{17}$ Concerning the stability of our results, different measures of openness are used. The estimations with alternative measures (exports plus imports over GDP, exports? share of GDP, imports? share of GDP and the volume of exports plus imports), show qualitative results similar to those presented in this section.

${ }^{18}$ We test whether openness is endogenous using a time lag as the instrument. According to the test, Chi-sq $(1)=0.88$ and $\mathrm{P}$-value $=0.3469$; openness can be treated as exogenous in the equation. The concern of endogeneity is thus ruled out. The IV panel data regression is presented in Appendix A. Another instrument that might work better than the lagged trade could be the distance to external markets (Redding and Venables, 2004). However, we do not account for information on bilateral trade.
} 
model with $\theta \neq 0$ and $\rho \neq 0$, i.e., with time-specific effects and the temporal trends of regions, is estimated. In columns (4) and (5), openness is measured by the level of imports and exports, respectively.

The first two regressions do not consider time fixed effects or/and regional time trends whereas the regressions (3)-(5) do consider these factors. The estimates of the latter are more precise because they separate the effects related to trade and those related to predetermined trends of concentration of regions. Although the differences are minor, we rely on the results of the last three regressions. 
Table 2: Trade effect in agglomeration within Colombian regions

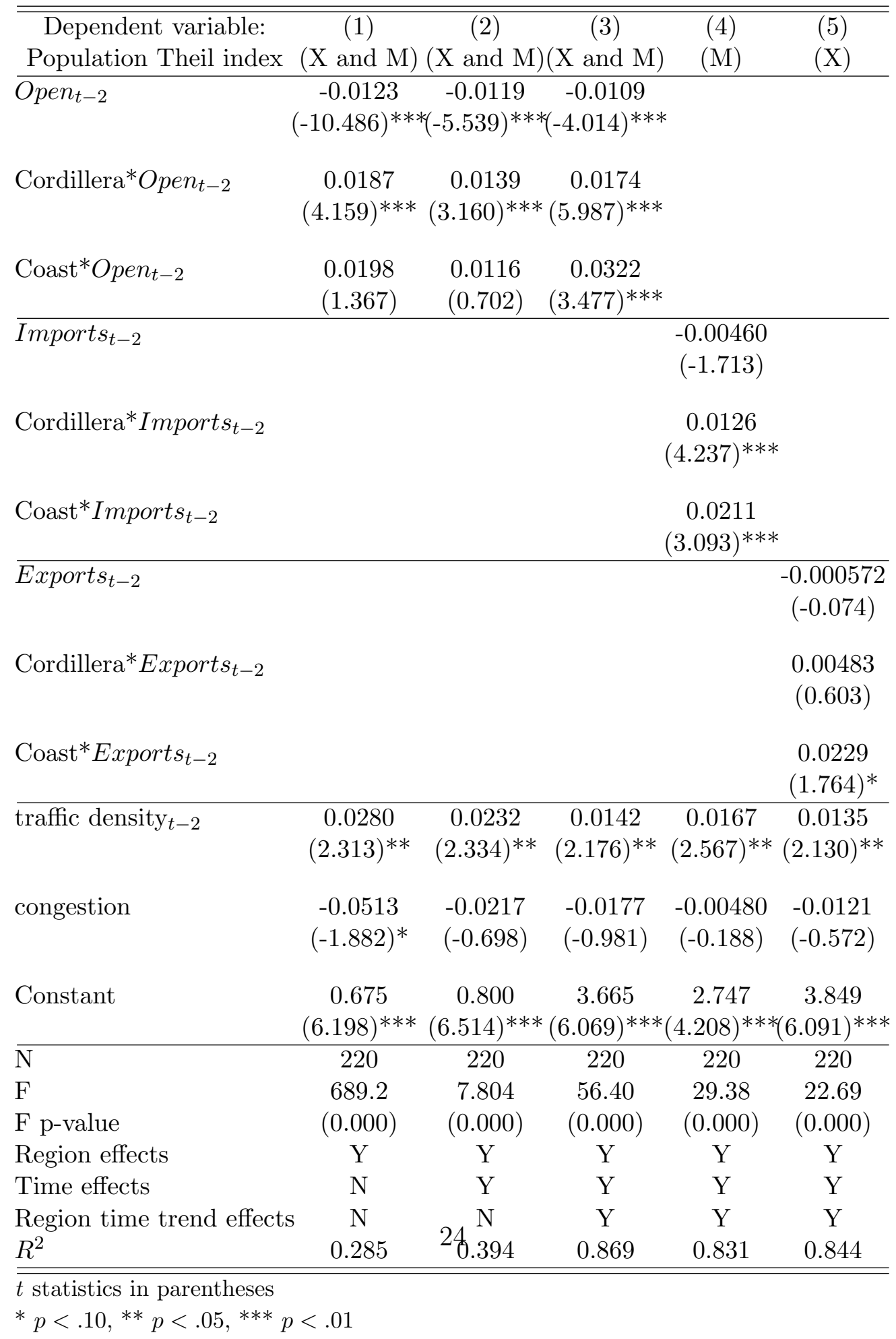


First, note that our coefficient of trade openness is interpreted as a function of the three elemental regions. The coefficient of $\ln \mathrm{Open}_{t-2}$ corresponds to the region of reference Amazon and Orinoquia; the coefficient of Cordillera $* \operatorname{lnOpen}_{t-2}$ corresponds to the effect of trade openness in regions of the Cordillera with respect to the region of reference. Finally, the coefficient of Coast $* \ln \mathrm{Open}_{t-2}$ corresponds to the effect of trade openness in Coastal regions with respect to the region of reference. The net effect of trade openness in the regions of the Cordillera/Coast is the sum of the coefficients of $\operatorname{lnOpen}_{t-2}$ and lnOpen $_{t-2} *$ Cordillera/Coast.

Given the expected effects discussed previously, two hypotheses are tested:

1. Trade openness increases less strongly the inequality of regions in the Amazon and Orinoquia compared with the other two types of regions, and

2. The effect of trade openness is higher in regions close to the international market (Coast) than in inland regions (Cordillera).

In sections 5.1 and 5.2, we present the comments concerning both hypotheses.

\subsection{Hypothesis 1: Inland regions experience a lower effect of trade openness in their inequality}

All regressions show that the effect of trade openness is significantly greater in the Cordillera regions and Coastal regions than in regions of the Amazon and Orinoquia. In fact, the latter experience a negative effect of trade on their inequality. This result indicates that inland regions in the Amazon and Orinoquia are more dispersed because of trade openness. Main cities of these regions do not attract further population driven by trade, perhaps because their size is not sufficiently large with respect to other cities in the same region. Dispersion is instead the resulting effect that arises from a weak home market effect of main cities in those regions. Another explanation could be related to the intuition ofKrugman and Livas Elizondo (1996). Because exporting- and importingoriented firms do not need to locate near the large market, forward and backward linkages vanish in the main city. However, note that the dispersion in these regions is less likely to be induced by congestion effects in main cities. 
Conversely, when trade increases in the Cordillera and Coastal regions, their main cities gain relevance in the regional economy and attract more population. Exporting and importing activities in search of good access to the international market locate in large cities which allow increasing returns to scale and stronger backward and forward linkages. In the case of the Cordillera regions, the size of the main cities representing their home market effect is the centripetal force enhanced by trade openness. Because we control for trends of agglomeration, the positive estimate is solely due to trade openness. Thus, historical factors can be discarded. In the case of Coastal regions, two centripetal forces are enhanced by trade: the home market of main cities and the location advantage.

According to the coefficient estimates, an increase of $100 \%$ in trade of the Cordillera and Coastal regions increases their population concentration in 0.0322 points and 0.0174 points, respectively, more than in the Amazon and Orinoquia regions.

In the period 2000-2010, trade in Coastal regions has increased 132\%, which has induced a $2.9 \%$ increase in their population Theil index. This increase corresponds to $95 \%$ of the increment in the Theil index in the period. In other words, the trade openness of the Coastal regions explains $95 \%$ of the increment in their spatial concentration of population. Conversely, the $172 \%$ increase of trade in the Cordillera regions between 2000 and 2010 has increased their spatial concentration of population by $2.2 \%$, which corresponds to $36 \%$ of the total increment of the Theil index in those regions.

The differences across regions might be related to their level of trade. The logarithm of trade in the Amazon and Orinoquia regions is 14.64 on average; in Coastal regions, it is 19.71, and in Cordillera regions, it is 19.58. According to the mean-comparison test, the difference between Amazon and Orinoquia regions with respect to both Cordillera and Coastal regions is significant. Thus, we observe that the effect of trade on inequality is negative in regions with a low level of trade. Moreover, the effect becomes positive in regions with a high level of trade. Based on this result, a U-shaped relationship between the level of trade and its effect on inequality can be inferred.

The concentration effect of trade is significant after controlling for local factors that affect agglomeration, namely traffic density in regions and congestion in main cities. These two variables allow distinguishing their effects from the effect of trade openness.

The variable of traffic density allows controlling for the effect of road infrastructure, which is generally of better quality close to the capital city. Hence, road density would 
be given in great part by the importance of the main city of each region. In fact, the estimate of this coefficient is positive and significant, suggesting that traffic flows are higher on roads close to the main city, inducing further agglomeration.

As mentioned previously, main cities are the centers from/to which exports and imports of other cities are transported. Thus, the effect of traffic density is very likely to be linked with trade. This aspect, which can disguise the effect of trade, is controlled in our specification by including this traffic density variable.

The other key element that is controlled in our models is the effect of congestion in main cities measured by the growth rate of daily urban transportation in service. Although this rate is negative, it is not always significant. According toKrugman and Livas Elizondo (1996), the effect of trade openness is influenced by strong congestion effects that lead firms to relocate far away from the main city. Nevertheless, the results of our model demonstrate that even in the presence of congestion effects in main cities, trade openness increases concentration toward them, inducing further spatial inequality within regions. Whereas congestion does induce dispersion in our model, external trade still provokes a concentrating effect, which could be because firms require a large market to trade. Thus, these results do not support the Krugman and Livas-Elizondo's (1996) hypothesis.

\subsection{Hypothesis 2: Coastal regions experience a higher effect of trade openness in their inequality than do Cordillera re- gions.}

Until now, we have proved the first hypothesis, that is, that trade generates a concentrationenhancing effect in Coastal regions and Cordillera regions, whereas regions in the Amazon and Orinoquia experience a negative effect of trade, inducing dispersion within them.

To test the second hypothesis, that is, that the effect of trade openness is greater in Coastal regions than in Cordillera regions, we assess the significant difference of their corresponding coefficient estimates. In the model in column (3) using the sum of exports and imports as a measure of trade openness, the effect of trade in the Cordillera is slightly lower than that of the Coast. According to the test of equality of coefficients, the difference is significant at the $9 \%$ level $(\mathrm{F}$ statistic $=3.14$, p-value $=0.0910)$.

To understand better the differences in trade effects across regions, we examine their differences in terms of exports and imports. Concerning imports (column 4), the null hypothesis of the equality of the coefficients is not rejected $(\mathrm{F}$ statistic $=1.26, \mathrm{p}$-value $=0.2750)$. 
In terms of exports (column 5), the effect in Cordillera regions is much lower than that in Coastal regions. Such a difference is significant at the $6 \%$ level (F statistic $=3.91$, pvalue $=0.0613)$.

The different effect of trade in terms of exports might be because the level of exports between the two groups is different. The average of the logarithm of exports from Coastal regions is 19.26, whereas the average of interior regions in the Cordillera is 18.44. According to the test, we reject the equality of those means (t-statistic $=3.03, \mathrm{p}$-value $=0.0027$ ). Coastal regions export more than Cordillera regions do, suggesting that the centripetal force coming from the location advantage prevails in the former. Moreover, the main cities of the Cordillera face higher internal transport costs (Nishikimi, 2008; Alonso-Villar, 1999; Crozet and Koenig, 2004), which limit their exports. The only centripetal force for them is thus the size of their market, which might constitute the main reason why spatial inequality within Coastal regions increases more than in Cordillera regions with trade openness.

Conversely, imports seem to produce a similar effect in the intra-inequality of both Coastal and Cordillera regions, possibly because the level of imports is almost similar between the two types of regions. Despite the large distance to ports, inland regions of the Cordillera import as much as do regions on the Coast. The first group of regions (Cordillera) records a mean of imports in logarithm of 18.54, whereas the second group (Coast) records a mean of 18.28. The mean-comparison test is not rejected (tstatistic $=0.91, \mathrm{p}$-value $=0.3632)$. Another possible reason that explains a similar effect of imports in the inequality of both types of regions leans on the diversity of products that the importing activity facilitates in main cities (Alonso-Villar, 1999). The utility of population increases with the diversity of services and goods. Main cities, no matter their location (Coast or Cordillera), are appropriate environments to produce positive externalities of diversity and attract more population, enhancing the inequality within their respective regions. Moreover, main cities become much larger because the importing activity is likely to be devoted to the development of the local industry. To determine to what extent industry is affected, analyzing imports by type of products would be useful. However, such an analysis is outside the scope of this study. Overall, we can state that the concentration-enhancing effect of trade within Coastal and Cordillera regions specifically comes from their level of imports.

Overall, the effect of trade remaining significant indicates that trade is sufficiently 
strong to shape the spatial configuration, a phenomenon that rarely changes.

Throughout this study, we were able to distinguish the effect of trade considering the heterogeneity of regions. The analysis using the sub-national geographical level has provided interesting and clear insights about the role of trade in the spatial configuration of cities within regions. By contrast, the results of the aforementioned studies (Ades and Glaeser, 1995; Henderson, 2000; Brülhart and Sbergami, 2009) analyzing the effect of trade at the national scale were rather inconclusive, possibly suggesting that the effect of trade is more explicit within regions than between regions. Thus far, this observation has not been directly addressed in theoretical studies, thus calling for further research, particularly in urban economics, given that trade openness affects the configuration of cities.

\section{Conclusions}

This study underscores that spatial disparities within countries come not only from interregional disparity but also from intra-regional disparity. In the Colombian case, the pattern of agglomeration is indeed revealed across geographical levels. Although this analysis focuses on Colombia, such a characteristic might be considered a general fact for all countries. Given that intra-regional inequality exists, this paper seeks to determine to what extent regional trade reinforces such a pattern. To answer this question, the effect of international trade on the concentration of population within sub-national regions of Colombia is estimated using panel data techniques.

Other conclusions stem from the empirical model estimating the effect of trade on intra-regional inequality. The results show that the effect of trade is different across types of regions. Overall, the Amazon and Orinoquia regions experience negative effects, i.e., trade induces dispersion within these regions. Conversely, regions of the Cordillera and the Coast tend to experience higher internal concentration induced by trade openness. The literature suggests two possible explanations behind these results: home market effect and location advantage effect.

On the one hand, main cities in the Cordillera gain further relevance due to their role in regional trade, i.e., the home market effect. On the other hand, main cities of Coastal regions experience more concentration induced by trade because of two effects. Apart from the home market effect, they enjoy good access to the international market, 
i.e., a location advantage effect. These results hold when considering the natural trend of inequality within regions over time, which means that the effect of trade is distinguished from that of the course of agglomeration. Overall, the effect of trade is sufficiently strong to overcome the patterns of concentration, which are hardly modifiable. Indeed, the increase of trade in the Cordillera and Coastal regions in the period explained $36 \%$ and 95\% of the increment in their Theil indexes, respectively. Furthermore, because the level of trade of the Amazon and Orinoquia regions is lower than that of the Cordillera and Coastal regions, we could deduce a U-shaped relationship between the level of trade and its effect on inequality. Overall, this empirical analysis, which demonstrates that spatial configuration of cities is shaped by trade openness, is a key finding that calls for the development of theoretical models considering a finer geographical level of analysis.

Finally, this study can be extended by differentiating the level of trade by type of products, which would provide promising results. For instance, such an analysis would shed light on the role of imports of manufacturing goods in bearing benefits for local innovation (Coe and Helpman, 1995; Coe et al., 1997) which, in turn, could affect spatial agglomeration. 


\section{References}

Ades, A. and Glaeser, E. (1995). Trade and circuses: explaining urban giants. Quartely Jornal of Economics, 110(1):195-227.

Akamatsu, T., Takayama, Y., and Ikeda, K. (2012). Spatial discounting, fourier,and racetrack economy: A recipe for the analysis of spatial agglomeration models. Journal of Economic Dynamics \& Control, 36(1):17291759.

Alonso-Villar, O. (1999). Spatial distribution of production and international trade: A note. Regional Science and Urban Economics, 29(3):371-380.

Aroca, P., Bosch, M., and Maloney, W. (2005). Spatial dimensions of trade liberalization and economic convergence: Mexico 1985-2002. Technical Report 3744, World Bank.

Behrens, K., Gaigné, C., and Ottaviano, G. I. (2007). Countries, regions and trade: On the welfare impacts of economic integration. European Economic Review, 51(5):12771301.

Brülhart, M., Crozet, M., and Koenig, P. (2004). Enlargement and the EU periphery: The impact of changing market potential. The World Economy, 27(6):853-875.

Brülhart, M. and Sbergami, F. (2009). Agglomeration and growth: Cross-country evidence. Journal of Urban Economics, 65(1):48-63.

Chiquiar, D. (2005). Why Mexico regional income divergence broke down. Journal of Development Economies, pages 257-275.

Coe, D. and Helpman, E. (1995). International R\&D spillovers. European Economic Review, 39(1):859-887.

Coe, D., Helpman, E., and Hoffmaister, A. (1997). North-south R\&D spillovers. Economic Journal, 107(1):134-149.

Crozet, M. and Koenig, P. (2004). EU enlargement and the internal geography of countries. Journal of Comparative Economics, 32(2):265-279.

Daumal, M. (2010). The impact of trade openness on regional inequality: The cases of India and Brazil. Technical report, Universite Paris 8 Vincennes-Saint-Denis, Universite Paris-Dauphine, LEDa, UMR DIAL. 
De-Ferranti, D., Perry, G. E., Foster, W., Lederman, D., and Valdés, A. (1998). Beyond the city. the rural contribution to development. World Bank Latin American and Caribbean Studies 32333, World Bank.

Deler, J. P. (1991). Geographie Universelle. Amerique Latine., chapter 20. Improbable Colombie. Paris: Maxeville.

Duranton, G. (2007). From cities to productivity and growth in developing countries. Working Paper tecipa-306, University of Toronto, Department of Economics.

Fajgelbaum, P. and Redding, S. J. (2014). External integration, structural transformation and economic development: Evidence from argentina 1870-1914. working paper 20217 2894, National Bureau of Economic Research, working paper 20217.

Fernandez, C. (1998). Agglomeration and trade: The case of colombia. Ensayos sobre politica economica. Banco de la Republica Colombia, 33:85-123.

Flórez, A. (2003). Colombia: evolución de sus relieves y modelados (In english: Colombia, reliefs evolution.). Unibiblios, ed.

Ge, Y. (2006). Regional inequality, industry agglomeration and foreign trade. Technical report, United Nations University, World Institute for Development Economics Research.

Gollin, D., Jedwab, R., and Vollrath, D. (2013). Urbanization without structural transformation. Technical report, University of Oxford, George Washington University, University of Houston.

Hansen, N. (1990). Impacts of small and intermediate-sized cities on population distribution: Issues and responses. Regional Development Dialogue, Spring, 11(1):60-76.

Hanson, G. H. (1997). Increasing returns, trade and the regional structure of wages. Economic Journal, 107(440):113-133.

Head, K. and Mayer, T. (2004). The empirics of agglomeration and trade. In Henderson, J. V. and Thisse, J. F., editors, Handbook of Regional and Urban Economics, volume 4. Elsevier.

Henderson, J. (1982). Systems of cities in closed and open economies. Regional Science and Urban Economics, 12(3):325-350. 
Henderson, J. and Kuncoro, A. (1996). Industrial centralization in indonesia. World Bank Economic Review, 10(3):513-540.

Henderson, J. V. (2000). The effects of urban concentration on economic growth. Technical report, National Bureau of Economic Research Working Paper 7503.

Henderson, V. (1994). Externalities and industrial development. NBER Working Paper.

Ikeda, K., Akamatsu, T., and Kono, T. (2012). Spatial period-doubling agglomeration of a coreperiphery model with a system of cities. Journal of Economic Dynamics and Control, 36(1):754-778.

Ikeda, K., Murota, K., Akamatsu, T., Kono, T., and Takayama, Y. (2014). Selforganization of hexagonal agglomeration patterns in new economic geography models. Journal of Economic Behavior \& Organization, 99(1):32-52.

INVIAS (2012). Traffic volumes 2010-2011. Technical report, National Institute of Roads (Instituto National de Vias in spanish).

Jedwab, R. (2013). Urbanization without structural transformation: Evidence from consumption cities in africa. Technical report, Department of Economics, George Washington University.

Jordaan, J. A. and Rodriguez-Oreggia, E. (2012). Regional growth in Mexico under trade liberalisation: how important are agglomeration and fdi? The Annals of Regional Science.

Kanbur, R. and Zhang, X. (2005). Fifty years of regional inequality in China: a journey through central planning, reform and openness. Review of Development Economics, 9(1):87-106.

Koujianou-Goldberg, P. and Pavcnik, N. (2007). The effects of the colombian trade liberalization on urban poverty. In Globalization and Poverty. University of Chicago Press.

Krugman, P. (1991). Increasing returns and economic geography. Journal of Political Economy, 99:483-499.

Krugman, P. and Livas Elizondo, R. (1996). Trade policy and the third world metropolis. Journal of Development Economics, 49(1):137-150. 
Krugman, P. and Venables, A. J. (1995). Globalization and the inequality of nations. The Quarterly Journal of Economics, MIT Press, 110(4):857-880.

Madariaga, N., Montout, S., and Ollivaudx, P. (2014). Regional convergence, trade liberalization and agglomeration of activities: an analysis of NAFTA and MERCOSUR cases. Technical Report bla04069, Universite Pantheon-Sorbonne (Paris 1).

Massiris-Cabeza, A., Espinoza-Rico, M. A., Ramirez-Castaneda, T., Rincón-Avellaneda, P., and Sanabria-Artunduaga, T. (2012). Procesos de ordenamiento en América Latina y Colombia (In english: Planning processes in Latin America and Colombia). Universidad Nacional de Colombia.

Monfort, P. and Nicolini, R. (2000). Regional convergence and international integration. Journal of Urban Economics, 48:286306.

Nishikimi, K. (2008). Specialization and agglomeration forces of economic integration. In Fujita, M., Kumagai, S., and Nishikimi, K., editors, Economic Integration in East Asia: Perspectives from Spatial and Neoclassical Economics. Edward Elgar Pub.

Paluzie, E. (2001). Trade policies and regional inequalities. Papers in Regional Science, 80:67-85.

Pellegrina, H. (2014). Roads, trade and urbanization in the tropics: Theory and evidence from the brazilian amazon. Technical report, Brown Univesity, Preliminary version.

Puga, D. (2002). European regional policies in light of recent location theories. Journal of Economic Geography, Oxford University Press, 2(4):373-406.

Ramirez-Grajeda, M. and Sheldon, I. (2009). Trade openness and city interaction. Munich Personal RePEc Archive.

Rauch, J. E. (1991). Comparative advantage, geographic advantage and the volume of trade. Economic Journal, 101(408):1230-1244.

Redding, S. and Venables, A. (2004). Economic geography and international inequality. Journal of International Economics, 62(1):53-82.

Sanguinetti, P. and Volpe-Martincus, C. (2009). Tariffs and manufacturing location in Argentina. Regional Science and Urban Economics, 39(2):155-167. 
Venables, A. J. (2005). Spatial disparities in developing countries: cities, regions and international trade. Journal of Economy Geography, 5(1):3-21.

\section{Appendices}

\section{A Agglomeration and trade openness, endogeneity test}

The presumption that openness could be endogenous is an important econometric issue that must be tested. Otherwise, an estimation violating the exogeneity of this regressor will be inconsistent. Then, we test whether openness need to be considered as endogenous in our estimation. To do so, we estimate an instrumental variable estimation for panel data treating Openness as endogenous instrumented with a time lag. We perform the test of endogeneity which is distributed as $\chi^{2}$ with degrees of freedom equal to the number of regressors tested. According to the test: Chi-sq(1) $=0.885$, P-value $=0.3469$, openness can be treated as exogenous in the equation. The concern of endogeneity is then ruled out. It is noteworthy that the coefficient estimates slightly change with respect to the results of the panel model estimation presented before. 
Table 3: Trade and intra-inequality, endogeneity test

\begin{tabular}{|c|c|}
\hline & $\begin{array}{c}(1) \\
\mathrm{FE}(\mathrm{X} \text { and } \mathrm{M})\end{array}$ \\
\hline$\overline{\text { Open }_{t-2}}$ & $\begin{array}{c}-0.0125 \\
(-4.221)^{* * *}\end{array}$ \\
\hline Cordillera* $^{*} \operatorname{Pp}_{t-2}$ & $\begin{array}{c}0.0190 \\
(5.761)^{* * *}\end{array}$ \\
\hline Coast $^{*}$ Open $_{t-2}$ & $\begin{array}{c}0.0337 \\
(9.349)^{* * *}\end{array}$ \\
\hline traffic density $_{t-2}$ & $\begin{array}{c}0.0146 \\
(4.050)^{* * *}\end{array}$ \\
\hline congestion & $\begin{array}{c}-0.0186 \\
(-2.265)^{*}\end{array}$ \\
\hline Region effects & Yes \\
\hline Time effects & Yes \\
\hline Region time trend effects & Yes \\
\hline $\mathrm{N}$ & 220 \\
\hline $\mathrm{F}$ & $33.91(0.000)$ \\
\hline$R^{2}$ & 0.7822 \\
\hline Endogeneity test & $0.885(0.3469)$ \\
\hline
\end{tabular}

